\title{
The Anglo-Norman Language and its Contexts, edited by Richard Ingham
}

\section{G. Matteo Roccati}

\section{Q OpenEdition}

1 Journals

\section{Édition électronique}

URL : https://journals.openedition.org/studifrancesi/2971

DOI : 10.4000/studifrancesi.2971

ISSN : 2421-5856

Éditeur

Rosenberg \& Sellier

\section{Édition imprimée}

Date de publication : 1 juillet 2013

Pagination : 425-426

ISSN : 0039-2944

\section{Référence électronique}

G. Matteo Roccati, «The Anglo-Norman Language and its Contexts, edited by Richard Ingham », Studi Francesi [En ligne], 170 (LVII | II) | 2013, mis en ligne le 30 novembre 2015, consulté le 02 février 2023. URL : http://journals.openedition.org/studifrancesi/2971; DOI : https://doi.org/10.4000/studifrancesi. 2971

Ce document a été généré automatiquement le 2 février 2023.

\section{(c) (†) $\ominus$}

Creative Commons - Attribution - Pas d'Utilisation Commerciale - Pas de Modification 4.0 International - CC BY-NC-ND 4.0

https://creativecommons.org/licenses/by-nc-nd/4.0/ 


\title{
The Anglo-Norman Language and its Contexts, edited by Richard Ingham
}

\author{
G. Matteo Roccati
}

\section{RÉFÉRENCE}

The Anglo-Norman Language and its Contexts, edited by Richard INGHAM, The University of York, York Medieval Press (Woodbridge, Boydell \& Brewer Ltd.), 2010, pp. X-184.

1 Le volume rassemble douze contributions issues de deux workshops tenus à Birmingham en 2007 et 2008. L'Introduction par Richard INGHAM, (1. Anglo-Norman: New Themes, New Contexts, pp. 1-7) présente rapidement le contenu du volume et son ambition: à partir de la constatation que le français insulaire est resté non seulement vivant jusqu'au XIve siècle, mais utilisé dans des domaines - juridique, commercial, littéraire - où manifestement il satisfaisait aux exigences de précision et de communication qui le faisaient préférer à l'anglais ou au latin, les différentes contributions essayent d'expliciter les formes et les raisons de cette permanence ainsi que le contexte dans lequel elle s'est réalisée. Richard INGHAM, 2. Later Anglo-Norman as a Contact Variety of French? (pp. 8-25) examine certaines caractéristiques de la langue (marqueurs de genre, formes pronominales, classes de conjugaison, expression du passé) qui permettent d'éclairer ses liens avec l'anglais et les rapports qui régissent les deux langues dans une situation de réel bilinguisme; Anthony LODGE, 3. The Sources of Standardisation in French Written or Spoken? (pp. 26-43), après avoir rapidement présenté les explications proposées par les différentes écoles au sujet de la standardisation du français, met l'accent sur le rôle qu'a dû jouer le développement urbain de Paris entre 1150 et 1250: la «koineisation» de la langue serait en premier lieu le résultat de l'immigration massive que la ville a connu pendant cette période, certaines formes relevées dans deux chartes de 1241 et 1260 le confirment.

2 Les articles suivants portent sur des domaines spécifiques où la langue a été utilisée: les traités sur l'économie domestiques et l'agriculture (William ROTHWELL, 4. Husbonderie and 
Manaungerie in Later Medieval England: A Tale of Two Walters, pp. 44-51), les documents, témoins des mélanges de langues, concernant la construction et la réparation des ponts à Exeter, Rochester et Leicester (David TROTTER, 5. Bridging the Gap: The (Socio)linguistic Evidence of Some Medieval English Bridge Accounts, pp. 52-62, avec transcription de deux pièces inédites datées de 1349 et 1365/6), les emprunts au français dans le lexique concernant les tissus et les vêtements (Mark CHAMBERS and Louise SYLVESTER, 6. From Apareil to Warderobe: Some Observations on Anglo-French in the Middle English Lexis of Cloth and Clothing, pp. 63-73), le langage utilisé dans l'armée et par les autorités anglaises sur le continent (Anne CURRY, Adrian BELL, Adam CHAPMAN, Andy KING and David SIMPKIN, 7. Languages in the Military Profession in Later Medieval England, pp. 74-93), le lexique judiciaire (Paul BRAND, 8. The Language of the English Legal Profession: The Emergence of a Distinctive Legal Lexicon in Insular French, pp. 94-101).

Enfin les quatre dernières contributions portent sur un projet destiné à préciser, si elles existent, les variantes régionales du français insulaire, et l'évolution de la langue dans le temps, (Jean-Pascal POUZET, 9. Mapping Insular French Texts? Ideas for Localisation and Correlate Dialectology in Manuscript Materials of Medieval England pp. 102-129), l'utilisation de l'article défini français - non marqueur de genre, mais indiquant l'introduction d'un mot anglais - dans des documents comptables du xve siècle (Laura WRIGHT, 10. A Pilot Study on the Singular Definite Articles «le» and «la» in Fifteenth-Century London MixedLanguage Business Writing, pp. 130-142), l'influence du français sur la syntaxe anglaise (Eric HAEBERLI, 11. Investigating Anglo-Norman Influence on Late Middle English Syntax, pp. 143-163), la coupure qui apparaît dans le dernier quart du XIV siècle dans le maniement $\mathrm{du}$ français insulaire, conséquence d'un changement dans son apprentissage vers le milieu du siècle (Richard INGHAM, 12. The Transmission of Later Anglo-Norman: Some Syntactic Evidence, pp. 164-182). Le volume est complété par l'index. 